\title{
The Moderating Effect of Shift Work on Lipid Pathway: An Application of Multi-Group Path Analysis Model
}

\author{
Shokofeh Maleki ${ }^{1}$, Mohammad Gholami Fesharaki ${ }^{1,{ }^{*}}$ and Mohsen Rowzati ${ }^{2}$ \\ ${ }^{1}$ Biostatistics Department, Faculty of Medical Sciences, Tarbiat Modares University, Tehran, Iran \\ ${ }^{2}$ Occupational Health Center, Mobarakeh Steel Company, Isfahan, Iran \\ "Corresponding author: Biostatistics Department, Faculty of Medical Sciences, Tarbiat Modares University, Tehran, Iran. Email: mohammad.gholami@modares.ac.ir
}

Received 2018 April 27; Revised 2018 July 18; Accepted 2018 August 04.

\begin{abstract}
Background: Previous studies have reported conflicting results concerning the association between shift work and variables such as blood pressure and lipid profile.

Objectives: The present study aimed to examine the moderating effect of shift work on lipid profile and blood pressure.

Methods: This cross-sectional study was done on steelworkers who worked in Esfahan's Mobarakeh Steel Company (EMSC) in the year 2017. In this study, workers were selected using random cluster sampling to investigate the moderating effect of shift work on lipid profile using the path analysis model in AMOS software.

Results: A total of 1549 workers (including 926 (60\%) shift workers and 623 (40\%) day workers) with a mean age of $24.17 \pm 6.11$ years participated in this study. The path analysis model showed a good fit index (RMSEA $=0.012, \mathrm{P}=0.010$ ). The path analysis results revealed that shift work moderating effect caused a decrease in the relationship between Triglyceride(TG) and Low-Density Lipoprotein (LDL) and between TG and LDL but increased the relationship between TG and Diastolic Blood Pressure.

Conclusions: Our findings showed a new evidence that shift work could have a moderating effect on blood pressure and lipid profile.
\end{abstract}

Keywords: Blood Pressure, Lipid Profile, Lipoproteins, Moderator, Path Analysis, Shift Work, Steel Worker, Triglycerides

\section{Background}

Industrialization in the world especially in steel industries has led to the widespread adoption of shift-work scheduling (1).

Shift work is an unusual pattern of work in comparison with Workday. This pattern in many industrial, economic, and service activities is an integral part of the provision of services $(2,3)$.

Previous studies have shown that nutrition shift work $(3,4)$, physical activity (4-6), obesity (7-9), blood pressure (BP) $(10,11)$, blood lipid variables (like triglyceride (TG), cholesterol (CHOL), Low- Density Lipoprotein (LDL), HighDensity Lipoprotein (HDL), and Fasting Blood Sugar (FBS)) are the most common risk factors for cardiovascular diseases (12-14).

For this reason, studying the association between the risk factors such as shift work and blood pressure, lipid variables, obesity, and lipid profiles is important.

The results of our study documented the strong impact of shift work on body weight gain, the risk of obesity, and blood pressure. These findings are in line with many studies that have reported a relationship between shift work and other lipid variables such as blood pressure (15-17) $\uparrow$, (18-20) $\downarrow$, Low-Density Lipoprotein (18-21) $\uparrow,(22) \downarrow$, HighDensity Lipoprotein $(23) \uparrow,(21,24) \downarrow$, Waist Circumference $(16,25)$, Body Mass Index $\uparrow(26-29)$, Fasting Blood Sugar (ineffective) (30), cholesterol $\uparrow(1), \downarrow$ (31), triglyceride $\uparrow(32), \downarrow$ (33), age $\uparrow(34)$, and weight $\uparrow(5,7-9)$.

\section{Objectives}

Given the importance of the issue, this study aimed to investigate the moderating effect of shift work on lipid profile and blood pressure.

\section{Methods}

A cross-sectional study that was approved by the Medical Ethics Committee of Tarbiat Modares University (code number: IR.TMU.REC.1395.398) was conducted on the workers of Esfahan's Mobarakeh Steel Company (EMSC) from 
January 1, 2017, until December 31, 2017 using a random cluster sampling method, in which the work area first was selected, and then the workers in this area were selected using simple sampling.

The inclusion criteria included official employment in the study year with at least two years of work experience, and the exclusion criteria included dismissal or unwillingness to participate in the study. The sample size was calculated as 1532 cases using $\mathrm{G}^{*}$ Power software $(\alpha=5 \%, \beta=95 \%$, effect size $=0.20, \mathrm{n} 1=1.5 \times \mathrm{n} 2$, and dropout rate $=15 \%)(35)$. In this study, blood pressure was measured in both arms in a sitting position after a five-minute rest using a calibrated mercury sphygmomanometer. In addition, laboratory variables were measured using the calibrated equipment. The scheduled shift time is presented in Gholami Fesharaki et al. study (18).

\subsection{Data Analysis}

In this study, a multi-group path analysis model (36) was employed in AMOS version 18 software. In the path analysis, GFI $>0.9$, RMSEA $<0.05$, and RCS $<2$ were considered as the good fit indices (37). P values of less than 0.05 and K-S test were used for statistical significance and data normality, respectively.

\section{Results}

This study was conducted on 1549 male workers (including 926 (60\%) shift workers and 623 (40\%) day workers) with a mean age of $43.14 \pm 6.08$. In Table 1, the correlation between the variables used in the study is reported based on the shift and day workers. The data revealed that the correlation between the majorities of variables was significant. The result of path analysis is presented in Table 2 and Figure 1. In this case, the path analysis indicated excellent goodness of fit results for the data. As can be seen in this table, all betas for direct effect had a significant relationship with the dependent variable. Results also showed that working in shifts tends to reduce the association between triglyceride and cholesterol as well as between triglyceride and low-density lipoprotein but increased the association between triglyceride and diastolic blood pressure.

\section{Discussion}

The results of this study showed the moderating effect of shift work on three path coefficients (triglyceride $\rightarrow$ cholesterol, triglyceride $\rightarrow$ low-density lipoprotein, and triglyceride $\rightarrow$ Diastolic Blood Pressure) in our model. Our findings showed that shift work tended to reduce the association between triglyceride and cholesterol and between

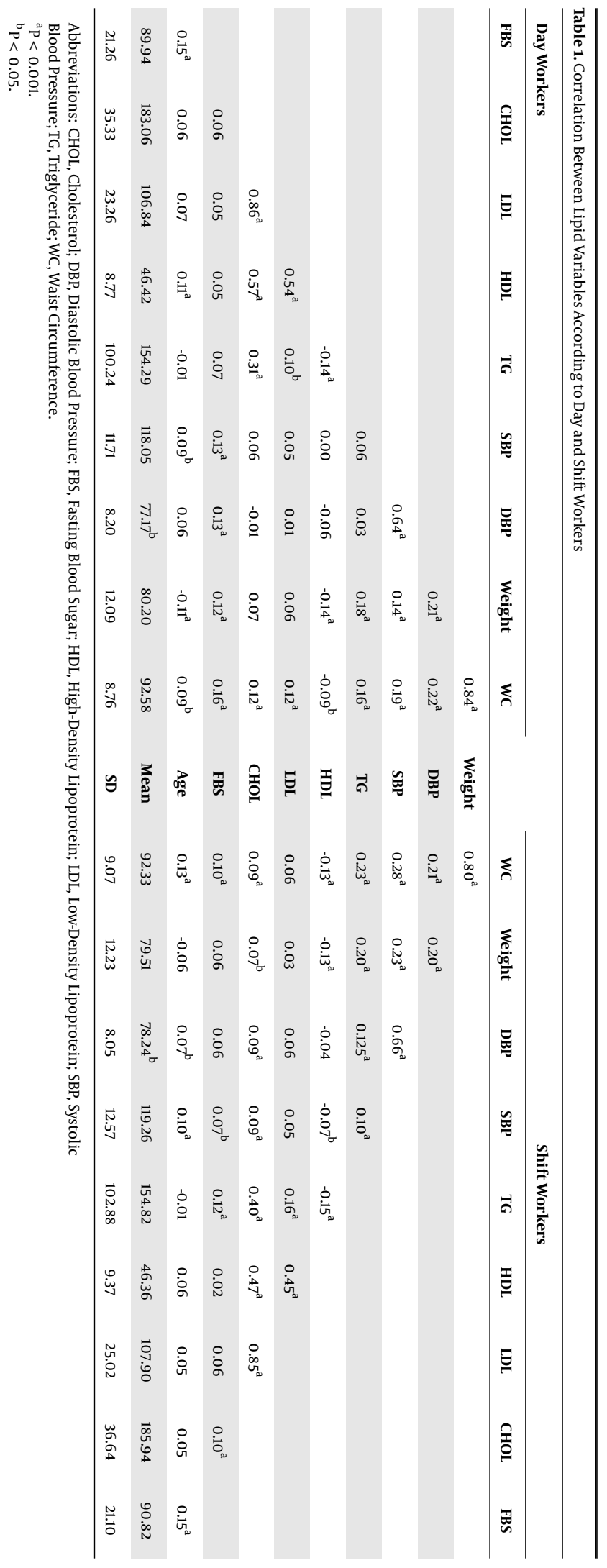




\begin{tabular}{|c|c|c|c|c|c|c|}
\hline \multicolumn{3}{|l|}{ Role of Variable } & \multirow{2}{*}{ Total } & \multirow{2}{*}{ Shift Workers } & \multirow{2}{*}{ Day Workers } & \multirow{2}{*}{ PValue } \\
\hline Independent & $\rightarrow$ & Dependent & & & & \\
\hline Age & $\rightarrow$ & FBS & $0.152^{* * * *}$ & $0.149^{* * * *}$ & $0.153^{* * *}$ & \\
\hline Age & $\rightarrow$ & WC & $0.112^{* * *}$ & $0.091^{*}$ & $0.131^{* * *}$ & \\
\hline Age & $\rightarrow$ & HDL & $0.052^{*}$ & $0.071^{*}$ & 0.036 & \\
\hline Age & $\rightarrow$ & Weight & $-0.177^{* * *}$ & $-0.186^{* * * *}$ & $-0.169^{* * *}$ & \\
\hline WC & $\rightarrow$ & TG & $0.198^{* * * *}$ & $0.156^{* * * *}$ & $0.227^{* * * *}$ & \\
\hline WC & $\rightarrow$ & Weight & $0.061^{*}$ & $0.858^{* * *}$ & $0.824^{* * *}$ & \\
\hline WC & $\rightarrow$ & LDL & $0.838^{* * *}$ & $0.104^{*}$ & 0.026 & \\
\hline WC & $\rightarrow$ & SBP & $0.242^{* * *}$ & $0.192^{* * * *}$ & $0.273^{* * *}$ & \\
\hline TG & $\rightarrow$ & HDL & $-0.127^{* * * *}$ & $-0.129^{* *}$ & $-0.123^{* * *}$ & \\
\hline TG & $\rightarrow$ & CHOL & $0.713^{* * *}$ & $0.273^{* * *}$ & $0.312^{* * *}$ & $* * *$ \\
\hline TG & $\rightarrow$ & DBP & $0.583^{* * *}$ & 0.694 & $0.497^{*}$ & *** \\
\hline TG & $\rightarrow$ & LDL & $0.121^{* * *}$ & $0.086^{*}$ & $0.151^{* * *}$ & $* * *$ \\
\hline Weight & $\rightarrow$ & DBP & $0.11^{* * *}$ & $0.127^{*}$ & $0.103^{*}$ & \\
\hline HDL & $\rightarrow$ & CHOL & $0.713^{* * *}$ & $0.225^{* * *}$ & $0.197^{* * *}$ & \\
\hline FBS & $\rightarrow$ & TG & $0.066^{*}$ & 0.047 & $0.085^{*}$ & \\
\hline LDL & $\rightarrow$ & CHOL & $0.713^{* * *}$ & $0.707^{* * *}$ & $0.197^{* * *}$ & \\
\hline Goodness of fit & & & RMSEA $=0.012$ & $\mathrm{GFI}=99 \%$ & Relative $\mathrm{Chi}=1.439$ & \\
\hline
\end{tabular}

triglyceride and low-density lipoprotein but increased the association between triglyceride and diastolic blood pressure.

A review of the published papers reveals conflicting findings. For example, Asare-Anane et al. (21), Suwazono et al. (1), Alefishat and Abu Farha (32), and Souza et al. (16) reported a significant association between shift work and low-density lipoprotein, cholesterol, triglyceride, and blood pressure. This is while Kantermann et al. (22), Uetani et al. (31), Akbari et al. (33), and some other studies (33, 37,38 ) found no relationship with low-density lipoprotein, cholesterol, triglyceride, and blood pressure.

The conflicting results of previous studies can be attributed to the fact that while shift work might not have a direct effect on blood pressure and lipid variables, not considering it as a moderating variable has caused conflicting results in these studies. Moreover, other factors such as healthy worker effect (18) and running SHIMSCO plan in EMSC (39) may help us to explain the mixed results.

In general, the findings of the present study support the moderating effect of shift work on blood pressure and lipid variables. To assess this relationship more accurately, further cohort studies adjusted for confounding factors such as occupational history, family history, and psychological factors (e.g., occupational stress and job satisfaction) are required. The major strengths of this study were sample homogeneity, large sample size, and applying a powerful statistical model for data analysis, which guaranteed the results of this study. The limitations of this study were that all employees participating in this study were male and since this study was carried out on steelworkers, the results could be more generalized to the heavy industry. In addition, any observed relationship in crosssectional studies does not imply a causality effect.

\section{Acknowledgments}

The authors gratefully acknowledge the financial support from Tarbiat Modares University and wish to thank all the personnel, especially the staff of the Industrial Medicine Department of EMSC, for their cooperation throughout the study.

\section{Footnotes}

Ethical Considerations: This cross-sectional study was approved by the Medical Ethics Committee of 


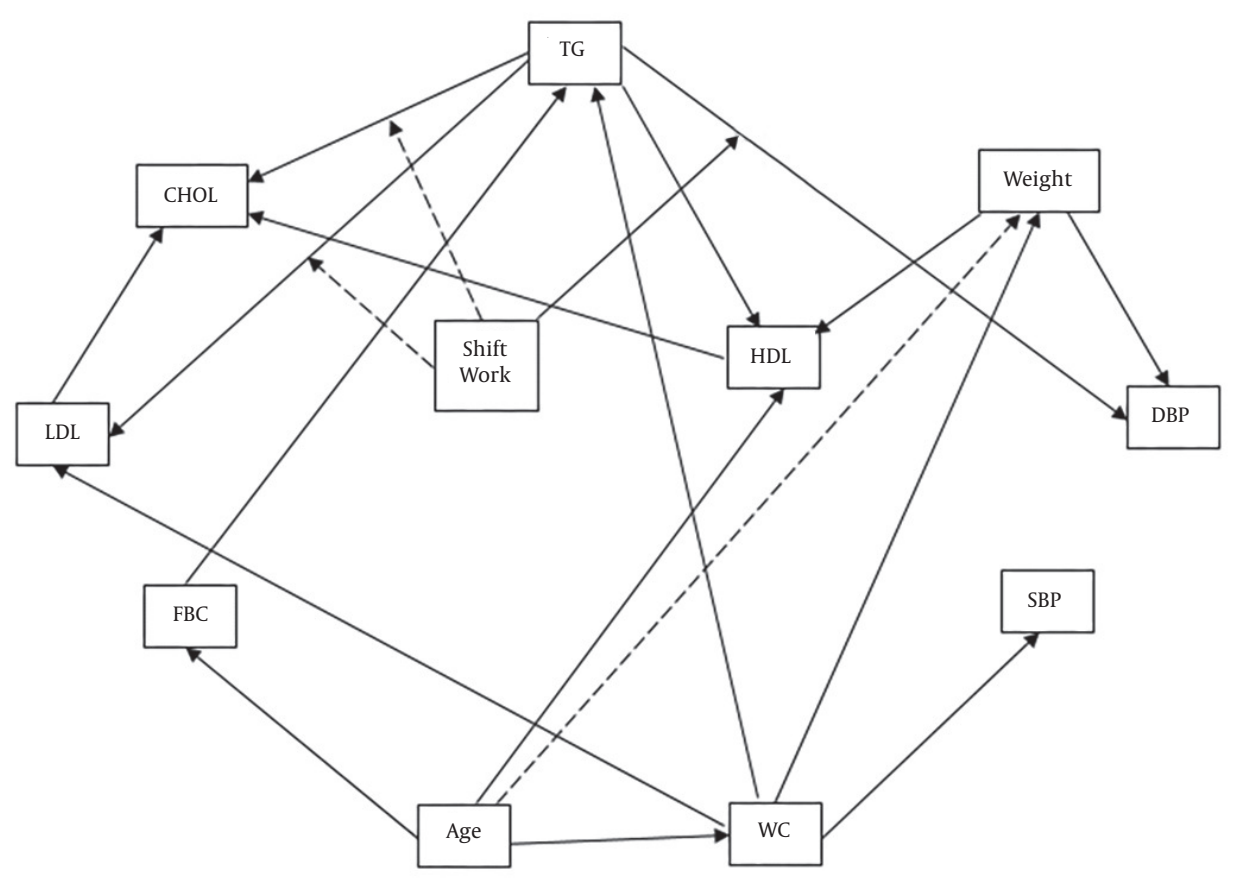

Figure 1. Pathway of blood pressure and lipid variable. Solid and dashed arrows represent increasing and decreasing betas, respectively. (CHOL, Cholesterol; DBP, Diastolic Blood Pressure; FBS, Fasting Blood Sugar; HDL, High-Density Lipoprotein; LDL, Low-Density Lipoprotein; SBP, Systolic Blood Pressure; TG, Triglyceride; WC, Waist Circumference).

Tarbiat Modares University, Tehran, Iran. (number: IR.TMU.REC.1395.398).

\section{Financial Disclosure: Tarbiat Modares University.}

Funding/Support: Tarbiat Modares University.

\section{References}

1. Suwazono Y, Uetani M, Oishi M, Tanaka K, Morimoto H, Nakada S, et al. Estimation of the benchmark duration of alternating shift work associated with increased total cholesterol levels among male Japanese workers. Scand J Work Environ Health. 2010;36(2):142-9. [PubMed: 20084348].

2. Gholami Fesharaki M, Rozati M, Tanhai AR. The longitudinal study of the relationship between work shift and blood pressure in workers of Mobarakeh Steel Company of Isfahan in 2007-2009. Arak Med Univ J. 2010;13(4).

3. Lee DH, Kang SK, Choi WJ, Kwak KM, Kang D, Lee SH, et al. Association between serum ferritin and hypertension according to the working type in Korean men: The fifth Korean National Health and nutrition examination survey 2010-2012. Ann Occup Environ Med. 2018;30:40. doi: 10.1186/s40557-018-0251-y. [PubMed: 29942520]. [PubMed Central: PMC5996563].

4. Rahmati-Najarkolaei F, Tavafian SS, Gholami Fesharaki M, Jafari MR. Factors predicting nutrition and physical activity behaviors due to cardiovascular disease in Tehran university students: Application of health belief model. Iran Red Crescent Med J. 2015;17(3). e18879. doi: 10.5812/ircmj.18879. [PubMed: 26019896]. [PubMed Central: PMC4441786].

5. Rahmati Najarkolaei F, Ghaffarpasand E, Gholami Fesharaki M, Jonaidi Jafari N. Nutrition and physical activity educational interven- tion on CHD risk factors: A systematic review study. Arch Iran Med. 2015;18(1):51-7. [PubMed: 25556387].

6. Bekkers MB, Koppes LL, Rodenburg W, van Steeg H, Proper KI. Relationship of night and shift work with weight change and lifestyle behaviors. J Occup Environ Med. 2015;57(4):e37-44. doi: 10.1097/JOM.0000000000000426. [PubMed: 25749131].

7. Barbadoro P, Santarelli L, Croce N, Bracci M, Vincitorio D, Prospero E, et al. Rotating shift-work as an independent risk factor for overweight Italian workers: A cross-sectional study. PLoS One. 2013;8(5). e63289. doi: 10.1371/journal.pone.0063289. [PubMed: 23675472]. [PubMed Central: PMC3651162].

8. Proper KI, van de Langenberg D, Rodenburg W, Vermeulen $\mathrm{RCH}$, van der Beek AJ, van Steeg H, et al. The relationship between shift work and metabolic risk factors: A systematic review of longitudinal studies. Am JPrev Med. 2016;50(5):e147-57. doi:10.1016/j.amepre.2015.11.013. [PubMed: 26810355].

9. Son M, Ye BJ, Kim JI, Kang S, Jung KY. Association between shift work and obesity according to body fat percentage in Korean wage workers: data from the fourth and the fifth Korea National Health and Nutrition Examination Survey (KNHANES 2008-2011). Ann Occup Environ Med. 2015;27:32. doi: 10.1186/s40557-015-0082-z. [PubMed: 26705475]. [PubMed Central: PMC4690414].

10. Esquirol Y, Perret B, Ruidavets JB, Marquie JC, Dienne E, Niezborala $\mathrm{M}$, et al. Shift work and cardiovascular risk factors: New knowledge from the past decade. Arch Cardiovasc Dis. 2011;104(12):636-68. doi: 10.1016/j.acvd.2011.09.004. [PubMed: 22152516].

11. Alpert MA, Omran J, Bostick BP. Effects of obesity on cardiovascular hemodynamics, cardiac morphology, and ventricular function. Curr Obes Rep. 2016;5(4):424-34. doi: 10.1007/s13679-016-0235-6. [PubMed: 27744513].

12. Salazar MR, Espeche WG, Aizpurua M, Leiva Sisnieguez BC, Leiva Sisnieguez CD, Dulbecco CA, et al. Risk of cardiovascular disease accord- 
ing to blood pressure categories in an argentinian cohort. RevFac Cien Med Univ Nac Cordoba. 2016;73(3):181-7. [PubMed: 27805555].

13. Toth PP. Triglyceride-rich lipoproteins as a causal factor for cardiovascular disease. Vasc Health Risk Manag. 2016;12:171-83. doi: 10.2147/VHRM.S104369. [PubMed: 27226718]. [PubMed Central: PMC4866746].

14. Sampson UK, Fazio S, Linton MF. Residual cardiovascular risk despite optimal LDL cholesterol reduction with statins: The evidence, etiology, and therapeutic challenges. Curr Atheroscler Rep. 2012;14(1):1-10. doi: 10.1007/s11883-011-0219-7. [PubMed: 22102062]. [PubMed Central PMC3697085].

15. Kuetting DLR, Feisst A, Sprinkart AM, Homsi R, Luetkens J, Thomas D et al. Effects of a 24-hr-shift-related short-term sleep deprivation on cardiac function: A cardiac magnetic resonance-based study. J Sleep Res. 2018. doi: 10.1111/jsr.12665. [PubMed: 29411477].

16. Souza BB, Monteze NM, de Oliveira FL, de Oliveira JM, de Freitas Nascimento S, Marques do Nascimento Neto R, et al. Lifetime shif work exposure: Association with anthropometry, body composition, blood pressure, glucose and heart rate variability. Occup Environ Med. 2015;72(3):208-15. doi: 10.1136/oemed-2014-102429. [PubMed 25540411].

17. Su TC, Lin LY, Baker D, Schnall PL, Chen MF, Hwang WC, et al. Elevated blood pressure, decreased heart rate variability and incomplete blood pressure recovery after a 12-hour night shift work.J Occup Health. 2008;50(5):380-6. [PubMed: 18654044].

18. Gholami Fesharaki M, Kazemnejad A, Zayeri F, Rowzati M, Akbari H. Historical cohort study of shift work and blood pressure. Occup Med (Lond). 2014;64(2):109-12. doi: 10.1093/occmed/kqt156. [PubMed: 24526704].

19. Gholami-Fesharaki M, Kazemnejad A, Zayeri F, Rowzati M, Sanati J, Akbari H. Multicenter historical cohort study of the relationship between shift work and blood pressure. ARYAAtheroscler. 2014;10(6):28791. [PubMed: 25815017]. [PubMed Central: PMC4354080].

20. Virkkunen H, Harma M, Kauppinen T, Tenkanen L. Shift work, occupational noise and physical workload with ensuing development of blood pressure and their joint effect on the risk of coronary heart disease. Scand J Work Environ Health. 2007;33(6):425-34. [PubMed: 18327510].

21. Asare-Anane $\mathrm{H}, \mathrm{Abdul}-\mathrm{Latif} \mathrm{A}$, Ofori EK, Abdul-Rahman M, Amanquah SD. Shift work and the risk of cardiovascular disease among workers in cocoa processing company, Tema. BMC Res Notes. 2015;8:798. doi: 10.1186/s13104-015-1750-3. [PubMed: 26682743]. [PubMed Central PMC4683766].

22. Kantermann T, Duboutay F, Haubruge D, Hampton S, Darling AL, Berry JL, et al. The direction of shift-work rotation impacts metabolic risk independent of chronotype and social jetlag-An exploratory pilot study. Chronobiol Int. 2014;31(10):1139-45. doi 10.3109/07420528.2014.957295. [PubMed: 25187988].

23. Karlsson BH, Knutsson AK, Lindahl BO, Alfredsson LS. Metabolic disturbances in male workers with rotating three-shift work. Results of the WOLF study. Int Arch Occup Environ Health. 2003;76(6):424-30. doi 10.1007/s00420-003-0440-y. [PubMed:12783235].

24. Guo Y, Rong Y, Huang X, Lai H, Luo X, Zhang Z, et al. Shift work and the relationship with metabolic syndrome in Chinese aged workers. PLoS One. 2015;10(3). e0120632. doi: 10.1371/journal.pone.0120632. [PubMed: 25761114]. [PubMed Central: PMC4356508].

25. Peplonska B, Bukowska A, Sobala W. Association of rotating night shift work with BMI and abdominal obesity among nurses and midwives. PLoS One. 2015;10(7). e0133761. doi: 10.1371/journal.pone.0133761. [PubMed: 26196859]. [PubMed Central: PMC4511417].

26. Buchvold HV, Pallesen S, Waage S, Bjorvatn B. Shift work schedule and night work load: Effects on body mass index - A four-year longitudinal study. Scand J Work Environ Health. 2018;44(3):251-7. doi: 10.5271/sjweh.3702. [PubMed: 29487940].

27. Buden JC, Dugan AG, Faghri PD, Huedo-Medina TB, Namazi S, Cherniack MG. Associations among work and family health climate, health behaviors, work schedule, and body weight. J Occup Environ Med. 2017;59(6):588-99. doi: 10.1097/JOM.0000000000001049. [PubMed: 28471768]. [PubMed Central: PMC5477673].

28. Gholami Fesharaki M, Kazemnejad A, Zayeri F, Rowzati M, Akbari H. Relationship between shift work and obesity a retrospective cohort study. J Mil Med. 2012;14(2):93-7.

29. Silva-Costa A, Rotenberg L, Coeli CM, Nobre AA, Griep RH. Night work is associated with glycemic levels and anthropometric alterations preceding diabetes: Baseline results from ELSA-Brasil. Chronobiol Int. 2016;33(1):64-72. doi:10.3109/07420528.2015.1115765. [PubMed: 26731697].

30. Ika K, Suzuki E, Mitsuhashi T, Takao S, Doi H. Shift work and diabetes mellitus among male workers in Japan: Does the intensity of shift work matter? Acta Med Okayama. 2013;67(1):25-33. doi: 10.18926/AMO/49254. [PubMed: 23439506].

31. Uetani M, Sakata K, Oishi M, Tanaka K, Nakada S, Nogawa K, et al. The influence of being overweight on the relationship between shift work and increased total cholesterol level. Ann Epidemiol. 2011;21(5):327-35. doi: 10.1016/j.annepidem.2011.01.001. [PubMed: 21458725].

32. Alefishat E, Abu Farha R. Is shift work associated with lipid disturbances and increased insulin resistance? Metab Syndr Relat Disord. 2015;13(9):400-5. doi: 10.1089/met.2015.0052. [PubMed: 26357004].

33. Akbari H, Mirzaei R, Nasrabadi T, Gholami-Fesharaki M. Evaluation of the effect of shift work on serum cholesterol and triglyceride levels. Iran Red Crescent Med J. 2015;17(1). e18723. doi: 10.5812/ircmj.18723. [PubMed: 25763276]. [PubMed Central: PMC4341371].

34. Gustavsen S, Sondergaard HB, Oturai DB, Laursen B, Laursen JH, Magyari $\mathrm{M}$, et al. Shift work at young age is associated with increased risk of multiple sclerosis in a Danish population. Mult Scler Relat Disord. 2016;9:104-9. doi: 10.1016/j.msard.2016.06.010. [PubMed: 27645354].

35. Gholami Fesharaki M, Kazemnejad A, Zayeri F, Sanati J, Akbari H. Using bayesian multilevel modeling for determining the relationship between shift work and blood pressure during a retrospective longitudinal study. Iran J Epidemiol. 2013;8(4):1-8.

36. Taylor AB, MacKinnon DP, Tein JY. Tests of the three-path mediated effect. Organ Res Methods. 2007;11(2):241-69. doi: $10.1177 / 1094428107300344$

37. Hamta A, Kazemnejad A, Gholami-Fesharaki M, Rowzati M. Simultaneous effect of shift work on blood pressure and lipid profile: A path analysis. Int J Occup Saf Ergon. 2018;24(1):68-72. doi: 10.1080/10803548.2017.1314139. [PubMed: 28385130].

38. Marqueze EC, Ulhoa MA, Moreno CR. Effects of irregular-shift work and physical activity on cardiovascular risk factors in truck drivers. Rev Saude Publica. 2013;47(3):497-505. [PubMed: 24346562].

39. Khosravi AR, Rowzati M, Gharipour M, Fesharaki MG, Shirani S, Shahrokhi S, et al. Hypertension control in industrial employees: Findings from SHIMSCO study. ARYA Atheroscler. 2012;7(4):191-6. [PubMed: 23205054]. [PubMed Central: PMC3413089]. 